\title{
A clonal Plasmodium falciparum population in an isolated outbreak of malaria in the Republic of Cabo Verde
}

\author{
A. P. AREZ ${ }^{1}$, G. SNOUNOU ${ }^{2 *}$, J. PINTO ${ }^{1}$, C. A. SOUSA ${ }^{3}$, D. MODIANO ${ }^{4}$, H. RIBEIRO ${ }^{3}$, \\ A. S. FRANCO ${ }^{1}$, J. ALVES ${ }^{5}$ and V. E. Do ROSARIO ${ }^{1}$ \\ ${ }^{1}$ Centro da Malária e outras Doenças Tropicais, Instituto de Higiene e Medicina Tropical, Universidade Nova de Lisboa, \\ Rua da Funqueira, 96, 1300 Lisbon, Portugal \\ ${ }^{2}$ Department of Infection and Tropical Medicine, Imperial College School of Medicine, Northwick Park Hospital, \\ Harrow, Middlesex HA1 $3 U \mathcal{F}, U K$ \\ ${ }^{3}$ Unidade de Entomologia Médica, Instituto de Higiene e Medicina Tropical, Universidade Nova de Lisboa, Rua da \\ Funqueira 96, 1300 Lisbon, Portugal \\ ${ }^{4}$ Istituto di Parassitologia, Università 'La Sapienza' di Roma, P. le Aldo Moro 5, 00185 Rome, Italy \\ ${ }^{5}$ Programa Nacional de Luta contra o Paludismo, Ministério da Saúde, Direcção Geral de Saúde, Praia, Cabo Verde, \\ C.P. 47
}

(Received 3 October 1998 ; revised 6 November 1998 ; accepted 6 November 1998)

SUMMARY

We present the first parasitological, molecular and longitudinal analysis of an isolated outbreak of malaria. This outbreak occurred on Santiago Island (Republic of Cabo Verde), a region where malaria is hypoendemic and controlled, and thus the population is considered non-immune. Blood samples were collected from the inhabitants over 1 month and during cross-sectional surveys in the following year. The presence and nature of the parasites was determined by PCR. Plasmodium falciparum was the only species detected. Genetic analysis revealed that the circulating parasites were genetically homogeneous, and probably clonal. Gametocytes were found throughout this period. Our data suggest that this represented a focal outbreak, resulting in the infection of at least $40 \%$ of the villagers with a clonal parasite line. Thus, $P$. falciparum infections can persist for at least 1 year in a substantial proportion $(10 \%)$ of the hosts. Implications for malaria control and the interpretation of epidemiological data are discussed.

Key words: clonality, epidemic, malaria, PCR, Plasmodium falciparum, Republic of Cabo Verde.

\section{INTRODUCTION}

The archipelago of Cabo Verde comprises 10 islands located in the Atlantic Ocean $500 \mathrm{~km}$ to the west of Senegal (Fig. 1). The climate is characterized by a dry season (December-June) and a wet season (July-November) with short and irregular rainfalls. Malaria which was previously endemic has been almost eradicated following a sustained control programme between 1940 and 1970. Infections are now only observed in Santiago Island (Ribeiro et al. 1980; Alves, 1994), the largest island of the archipelago $\left(991 \mathrm{~km}^{2}\right)$. Approximately 90000 inhabitants (half of the Cabo Verde population) reside on Santiago island, where Praia, the capital of the Republic, is also situated (Fig. 1). A few episodes of resurgence were observed during the last 20 years (Alves, 1994): in 1978 (800 cases, with 13 deaths) and in 1988 (800 cases, with 12 deaths). These epidemics were considered to have arisen because of surges in the influx of immigrants, principally from

* Corresponding author: Department of Infection and Tropical Medicine, Imperial College School of Medicine, Northwick Park Hospital, Harrow, Middlesex HA1 3UJ, UK. Tel: +440181869 3507. Fax: +4401818693504. E-mail: g.snounou@ic.ac.uk the Republic of Guiné Bissau and the Republic of São Tomé e Príncipe, both endemic for malaria (Alves, 1994). The number of recorded cases between 1990 and 1994, inclusive, totalled 140 with only 2 cases for 1994 (Alves, 1994). These presumed autochthonous cases presented mainly with Plasmodium falciparum, usually during or immediately after the wet season. $P$. malariae and $P$. ovale have rarely been observed. The malaria vector is thought to be Anopheles arabiensis, the only member of the gambiae complex recorded on the archipelago since 1982 (Cambournac, Petrarca \& Coluzzi, 1982).

An outbreak of malaria was detected in October 1995 in the village of Achada Leite (Island of Santiago). Within 1 week of the diagnosis of the first infection, 27 of the 31 persons who presented to the local hospital were diagnosed positive for $P$. falciparum. Active case detection was initiated and all persons positive for malaria or with symptoms were treated by chloroquine. Collection of blood samples for the analysis of parasites by PCR was also initiated. Cross-sectional surveys were carried out until November 1996. P. falciparum was the only species detected by microscopy and by PCR. Molecular analysis of 3 polymorphic parasite genes, indicated that only 1 genetically homogeneous 

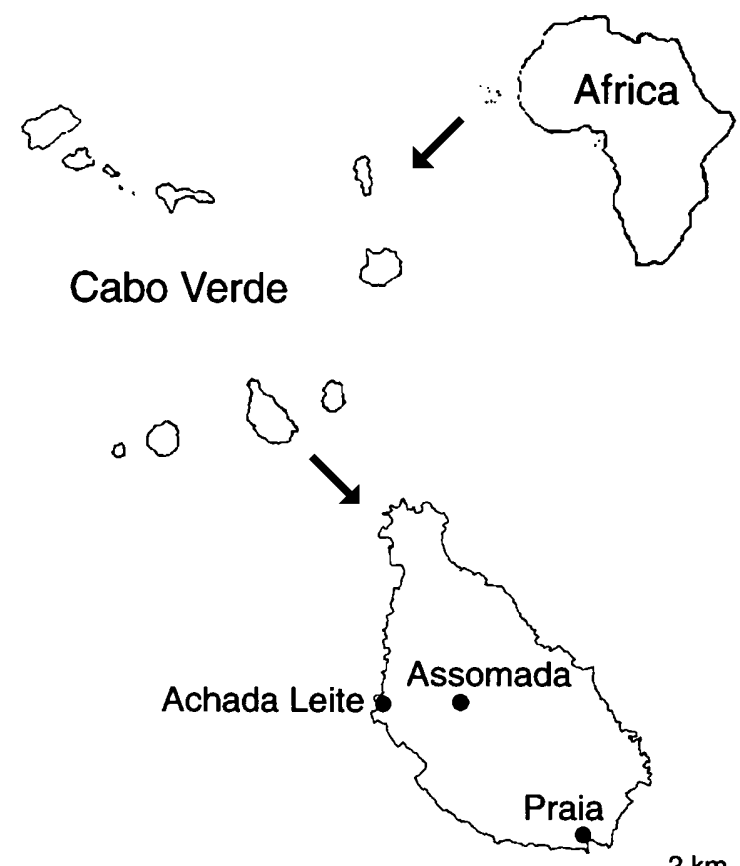

Santiago

2 km

Fig. 1. Geographical location of the Cabo Verde Archipelago, and the village of Achada Leite on Santiago Island.

parasite line was present throughout the study. One year after the outbreak, $10 \%$ of the inhabitants still harboured asexual and sexual stage parasites of the same line. Parameters related to the epidemiology of falciparum malaria and its control are discussed in the light of this unique outbreak.

\section{MATERIALS AND METHODS}

\section{Study area and sample collection}

The study was conducted in Achada Leite, $70 \mathrm{~km}$ from Praia on Santiago Island. The village, with approximately 200 inhabitants distributed in 35 houses, is located in the Santa Catarina district (41584 inhabitants). The health care of the villagers is exclusively provided by the hospital at Assomada, at a distance of $24 \mathrm{~km}$ from the village. Finger-prick blood collections were carried out during 5 crosssectional surveys: November/December $1995(n=$ $60)$, February $1996(n=83)$, May $1996(n=80)$, June $1996(n=36)$, August $1996(n=35)$, and November $1996 \quad(n=95) . \quad$ Whenever feasible, collections were made from the same individuals. Thin and thick smears were immediately made for microscopical examination after Giemsa staining. A drop of blood was spotted and dried on Whatman no. 4 filter paper and was used to prepare the template for PCR analysis. In a subset of cases, blood was also obtained by venepuncture and used for serological assays, or to initiate in vitro culture of P. falciparum. Two mosquito collections were made: one during the dry season (3-18 February 1996) and one during the wet season (22-31 October 1996). For the first collection, indoor resting captures with mechanical aspirators and indoors/outdoors CDC light trap captures were undertaken. For the second collection, field capture methods were further enhanced by pyrethroid indoor spraying, and overnight human bait captures. For both collections, larvae were captured by the standard methods and reared in the local laboratory. All mosquitoes identified as Anopheles gambiae s.l. were kept dry at room temperature in individual silica-gel filled tubes.

\section{In vitro chloroquine resistance}

Parasites from 5 subjects which were successfully established in in vitro culture were tested for susceptibility to chloroquine, using the World Health Organization's standard methodology (Rieckman et al. 1978). The 3D7 clone of $P$. falciparum was used as a susceptible control (Bayoumi, Babiker \& Arnot, 1994). Assays were performed in multi-well titre plates in candle-jars, for $24-72 \mathrm{~h}$ at $37^{\circ} \mathrm{C}$. Parasites were considered to be resistant if schizont maturation was observed in the presence of at least $8 \mathrm{pmol} / 100 \mu \mathrm{l}$ chloroquine.

\section{Anti-CSP antibody detection}

The humoral response against the CSP antigen of $P$. falciparum was evaluated for 14 serum samples, collected in May/June 1996, with a Sclavo (Siena, Italy) ELISA kit based on (NANP) $)_{40}$ repeat region of the antigen (Habluetzel, Esposito \& Lombardi, 1989). Each sample was tested twice. The cut-off value for seropositivity $(\mathrm{OD}=0 \cdot 09)$ was the mean plus 3 standard deviations of the values obtained for 8 negative Italian sera. Four human sera from Burkina Faso patients highly reactive to $P$. falciparum circumsporozoite protein were used as positive controls.

\section{PCR genotyping and sequencing}

DNA was prepared as previously described (Snounou et al. 1993) from approximately $100 \mu 1$ blood samples dried on filter paper or from in vitro culture parasites. Briefly, erythrocytes were lysed by incubation in PBS supplemented with $0.05 \%$ saponin, and the parasites recovered by centrifugation. The material was then incubated in lysis buffer (40 mм Tris, pH 8.0; 80 mм EDTA, pH 8.0; $\%$ SDS, pH 7.2), and the DNA purified by sequential phenol and phenol-chloroform extraction followed by an ethanol precipitation. DNA was resuspended in $20 \mu 1$ of TE buffer $(10 \mathrm{~mm}$ Tris, $\mathrm{pH} 8.0 ; 0.1 \mathrm{~mm}$ EDTA, pH 8.0).

Detection and speciation of parasites was achieved by nested-PCR amplification of the small subunit ribosomal RNA genes, as previously described 
(Snounou et al. 1993). P. falciparum parasites were characterized by using, as genetic markers, 3 unlinked single-copy genes (Viriyakosol et al. 1995), thus only 1 allelic variant is observed in the haploid genome of the malaria parasite in the human host. These were the merozoite surface proteins 1 (msp1), the merozoite surface protein 2 ( $m s p 2)$ and the glutamate rich protein (glurp). Each of these genes contains a highly polymorphic region composed of repeated units: block 2 of msp1 (Certa et al. 1987; Tanabe et al. 1987), block 3 of $m s p 2$ (Smythe et al. 1990) and RII of glurp protein (Borre et al. 1991). In addition to size differences the allelic variants of $m s p 1$ and $m s p 2$ also fall in 3 (K1, MAD20 and RO33) or 2 families (FC27 and 3D7/IC) respectively, defined by the sequence of the repeat units. Genotyping of the parasites was performed by nested PCR amplification (Snounou et al., manuscript in preparation). Briefly, oligonucleotides hybridizing to conserved sequences outside the polymorphic regions of the 3 genes were used in the first reaction. The product of this first reaction was then used to initiate 6 separate amplification reactions: one for the RII region of glurp and one for each of the allelic families of $m s p 1$ and $m s p 2$. The block 17 of $m s p 1$ was amplified in further nested PCR reaction, using the following oligonucleotide primers: M1-B17OF (5'CCTTTTTAAAAAATATTGAGACCTTATA$\left.3^{\prime}\right)$ and M1-B17OR (5'-AATGAAACTGTATAATATTAACATGAGTAT-3') in a first amplification reaction, and M1-B17NF (5'-ATGTTAAACATTTCACAACACCAATG-3') and M1B17NR (5'-GAATGATATTCCTAAGAAGTTAGAGGAACT-3') in the second.

In all cases $1 \mu \mathrm{l}$ of DNA template (approximately the equivalent of $5 \mu 1$ of whole blood) was used in the first amplification reaction. Similarly $1 \mu 1$ of the product of the first reaction was used as a template for the second nested reaction. PCR reactions were carried out in a total volume of $20 \mu \mathrm{l}$, containing $2 \mathrm{mu}^{\mathrm{MgCl}}{ }_{2}, 50 \mathrm{~mm} \mathrm{KCl}, 10 \mathrm{~mm}$ Tris, $\mathrm{pH} 8 \cdot 3$ ( $\mathrm{HCl}), 0 \cdot 1 \mathrm{mg} / \mathrm{ml}$ gelatine, $125 \mu \mathrm{M}$ of each of the 4 deoxyribonucleotide triphosphates, $125 \mathrm{~nm}$ of each oligonucleotide primer and 0.4 units of AmpliTaq Polymerase (Perkin Elmer Cetus, USA). The PCR assays were carried out in a programmable thermal controller (Perkin Elmer Cetus, USA), with the following conditions: 1 cycle, denature at $95{ }^{\circ} \mathrm{C}$ for $5 \mathrm{~min}$, anneal at $58^{\circ} \mathrm{C}$ for $2 \mathrm{~min}$ (for the second reaction $58{ }^{\circ} \mathrm{C}$ for glurp, and $61{ }^{\circ} \mathrm{C}$ for the $m s p 1$ and $m s p 2$ allelic families), extend at $72{ }^{\circ} \mathrm{C}$ for $2 \mathrm{~min}$, followed by 24 cycles (29 cycles for the nested reactions); denature at $94^{\circ} \mathrm{C}$ for $1 \mathrm{~min}$; anneal at the appropriate temperature for $2 \mathrm{~min}$, and a final extension at $72^{\circ} \mathrm{C}$ for $5 \mathrm{~min}$. The reaction is completed by reducing the temperature to $20^{\circ} \mathrm{C}$. PCR products were analysed by electrophoresis on MetaPhor ${ }^{\circledR}$ agarose gels, stained by ethidium bromide staining and visualized under UV trans- illumination. To control for contamination, a blank sample was included for each group of 5 field samples throughout the DNA extraction and PCR analysis steps.

Identification of mosquitoes of the A. gambiae complex was achieved by PCR amplification (Scott, Brogdon \& Collins, 1993; Pinto et al. 1997). DNA was extracted from each mosquito using potassium acetate, precipitated with $95 \%$ ethanol (Collins et al. 1988), and resuspended in $50 \mu 1$ of sterile water. Two positive controls, A. gambiae s.s and A. arabiensis, and a negative control were included with amplification.

\section{Sequencing of amplified fragments}

The PCR products from amplification of the polymorphic block 2 and conserved block 17 of $m s p 1$, and the repeat region of $m s p 2$ were purified using the Wizard ${ }^{\circledR}$ PCR Preps DNA purification Systems Kit (Promega), and cloned into the pCR2.1 plasmid using the Original TA Cloning kit (Invitrogen). Sequencing of positive clones ( 1 or 2 for each fragment cloned) was carried out by the dideoxy chain termination method, using the T7 Sequenase Quick-Denature Plasmid Sequencing kit (Amersham).

\section{RESULTS}

\section{Epidemiological and parasitological observations}

The possibility that malaria infections might afflict the inhabitants of Achada Leite was first raised late in October 1995. Inhabitants from this village had been reporting to the closest hospital at Assomada since early October, with symptoms of headache and fever. The first confirmed malaria case was recorded on 25 October 1995, and 5 positive smears were observed by the end of October 1995. A team from the Programa Nacional de Luta contra o Paludismo (PNLP) was then dispatched to the village and on 31 October, 15 out of 16 febrile patients were diagnosed by optical microscopy (OM) as having $P$. falciparum. Treatment was administered: chloroquine, a total of $25 \mathrm{mg} / \mathrm{kg}$ body weight given in 4 doses $(10 \mathrm{mg} / \mathrm{kg}$ followed by $5 \mathrm{mg} / \mathrm{kg} 6,24$ and $48 \mathrm{~h}$ late), and primaquine in a single dose of $0.75 \mathrm{mg} / \mathrm{kg}$ body weight. Active case detection was immediately initiated, and all smear-positive persons irrespective of clinical status, and smear negative persons with symptoms consistent with malaria, were treated as above. On 2 November 1995, 27 other inhabitants were examined: the 13 who were found to harbour parasites were all febrile, while only 3 of the 14 who were microscopically negative had fever. The geometric mean asexual parasitaemia for these 28 patients was 4550 parasites/ $\mu 1$ (range 250-102000). Unfortunately records were not kept for all the patients to whom treatment was administered in the 


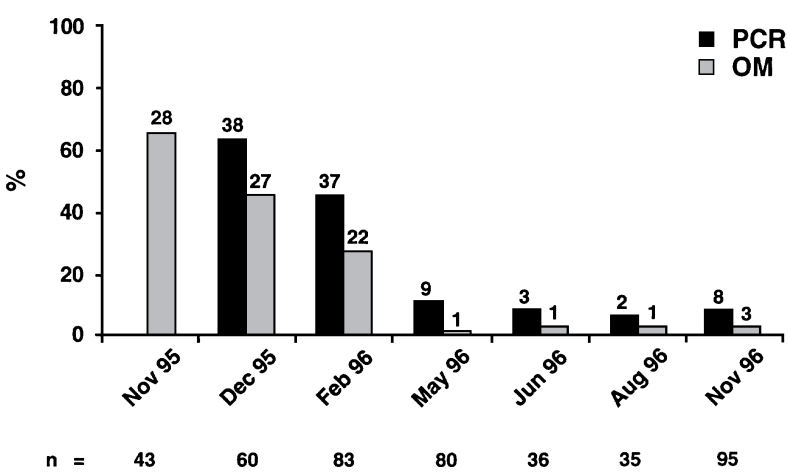

Fig. 2. Percentage prevalence of positive samples during the cross-sectional surveys. The actual number of villagers sampled in each survey $(n)$ is indicated below the $\mathrm{x}$-axis. The number of persons found positive for parasites by optical microscopy (OM) or by PCR analysis are indicated above the corresponding bars.

following weeks. Nonetheless collection of blood samples for the analysis of this outbreak was initiated at the end of November 1995. Cross-sectional surveys were subsequently made on 5 separate occasions, the last in late October 1996. Blood samples were analysed for the presence of parasites by PCR, and smears examined by OM. In all positive samples only $P$. falciparum could be detected.

All inhabitants found positive by OM were treated, and generally only mild symptoms (headache and fever) were verbally reported during the course of the surveys. Only 1 person in February 1996 required admission to hospital. In view of the proportion of positive persons in February 1996, poor compliance with the chloroquine treatment was suspected, and a single Fansidar dose $(500 \mathrm{mg} / \mathrm{kg})$ was subsequently used instead of chloroquine. Venous blood samples were also collected from 5 infected individuals in February 1996, and the parasites established successfully in in vitro culture. These parasites were considered to exhibit chloroquine resistance since schizont maturation was observed in the presence of $16 \mathrm{pmol}$ chloroquine/ $100 \mu 1$. This conclusion is supported when treatment failures are considered. Thus of the 16 people known to have been treated in early November 1995, parasites could still be demonstrated in the blood of 11 (OM or PCR), 1 month later. The rate of treatment failure, ascertained 2-3 months following treatment, is also high, $47 \%$ as calculated when all patients known to have been treated in November and December 1995, were re-examined (OM or PCR) in February 1996.

The parasite prevalence throughout the study is given in Fig. 2. PCR analysis proved, as expected, more sensitive than OM, and these results have been used to calculate prevalence values. Approximately half of the persons surveyed were found to have circulating parasites in early December 1995, and February 1996, 1 and 3 months respectively after the start of the outbreak. The corresponding geometric mean asexual parasitaemias for samples found to be microscopically positive during these 2 surveys were 2420 parasites $/ \mu 1$ (range 1000-15000) and 2960 parasites/ $\mu 1$ (range 200-200000). From May 1996 to November 1996, the prevalence was only found to be close to $10 \%$, and asexual parasites when found by microscopy did not exceed 10000 parasites $/ \mu 1$. Blood samples containing gametocytes were found throughout the study period, except in the August 1996 samples: 1 in November 1995, 6 in December 1995, 8 in February 1996, 1 each in May and June 1996, and finally 2 in November 1996.

The cumulative total of persons surveyed at least once between November 1995 and November 1996 was 203 (age range 4 months to 86 years). Thus the whole population of the village was effectively surveyed, although for some of the inhabitants only 1 sample could be obtained during the study period. Parasites were found at least once in a total of 83 different people $(41 \%$ of the inhabitants). No significant differences in the distribution of infections could be found between male and female inhabitants (41/97 and 42/106 respectively). Similarly, distribution of malaria between children and adults was also comparable (39/89 for the $0-14$ years old group, and 44/114 for those older than 15).

In May and November 1996 samples were also collected from the inhabitants of Charco, the closest village to Achada Leite (less than $1 \mathrm{~km}$ ). Three $P$. falciparum-positive samples were obtained ( 1 by $\mathrm{OM}$ and PCR, and 2 by PCR only) from the 112 samples collected. Genotyping analysis showed the same pattern as that obtained for all the Achada Leite samples.

\section{Entomological data}

Anti-mosquito measures were stepped-up by PNLP personnel as soon as malaria was found in Achada Leite, and few adult mosquitoes could be caught in November and December 1995. Nonetheless 2 collections were further attempted in February and November 1996. A total of $241 \mathrm{~A}$. gambiae s.l. were captured, and all identified as $A$. arabiensis by PCR. However, apart from 4 adults, the majority of insects were identified from laboratory-reared larvae collected from known breeding sites. Eggs, larvae of all stages and pupae were found together in the breeding sites. A. pretoriensis was the only other anopheline identified, and Culex ethiopicus, C. pipiens s.l., C. tigripes, Aedes aegypti and Culiseta longiareolata were also found.

Serum samples were also obtained from 14 individuals during May or June 1996. These samples were tested by ELISA for the presence of antibodies to the circumsporozoite protein (CSP) of $P$. falciparum. All 14 individuals had been found to be positive for $P$. falciparum at least once in previous 


\title{
msp1 Block 2
}

NEGTSGTAVT TSTPGSSGSV TSGGSGGSVA SVASGGSGGS GNSRRTNPSD

*

\section{msp1 Block 17}

\author{
MLNISQHQCV KKQCPENSGC FRHLDEREEC KCLLNYKQEG DKCVENPNPT CNENNGGCDA \\ * $Y$ \\ DATCTEEDSG SSRKKITCEC TKPDSYPLFD GIFCSSSNFL GISF \\ $T$ D V \\ $\mathrm{L}$
}

\section{msp2 Block 3}

\author{
RSMAESKPPT GASGNPPAGA SGNPPAGAGA GASGSAGAEG SSSTPATTTT TITTNDAEAS \\ * $S$ \\ TSTSSENPNH NNAKTNPKGK EVQEPNKANT ETQNNSNVQQ DSQTKSNVPP TQDADTKSPT \\ $\mathrm{G}$
}

\section{AQPEQAENSA PT $\underline{A E Q T E S P E} \underline{\text { LQ }}$}

Fig. 3. Amino acid sequence of regions of $m s p 1$ and $m s p 2$, amplified from selected samples (see text). Underlined sequences indicate regions which correspond to the oligonucleotide primers. An asterisk (*) below the corresponding amino acid indicates codons where synonymous mutations were found. The alternate amino acid when nonsynonymous mutations were found is placed below its corresponding position.

surveys. The optical density (OD) values of the positive controls from Burkina Faso ranged from 0.556 to 0.897 . Six of the sera from Achada Leite were found to be positive with $\mathrm{OD}$ values ranging from $0 \cdot 223$ to $1 \cdot 459$. Two of the persons who tested positive had parasites in May or June 1996, as did 3 of those who gave a negative ELISA results.

\section{Genetic analysis of the $\mathrm{P}$. falciparum parasites}

PCR genotyping was carried out for all samples found to contain $P$. falciparum. Three highly polymorphic genetic markers have been used to characterize $P$. falciparum parasites. Variable repetitive regions of the single copy genes $m s p 1, m s p 2$ and glurp were targeted by PCR. Amplification could not be obtained using 15 of the samples, most of which had very low parasitaemia undetected by microscopy. A single allelic variant identical for all samples was found for each of the 3 genetic markers. The size of each variant was estimated from its electrophoretic mobility: $1100 \mathrm{bp}$ for glurp, $150 \mathrm{bp}$ for block 2 of $m s p 1$ belonging to the MAD20 family, and $430 \mathrm{bp}$ for the block 3 of $m s p 2$ belonging to the 3D7/IC family. PCR analysis of parasites which were successfully established in in vitro culture was also carried out (both at the start and after 5-12 erythrocytic cycles), and revealed the same pattern. Since blood-stage parasites are haploid, the presence of only 1 allelic variant indicates a parasite population of very limited diversity. However, alleles of the same size but which differ in sequence are known to occur. Thus, the sequences of 2 of the amplified fragments, $m s p 1$, block 2 and $m s p 2$ block 3, were determined for samples obtained from 5 different persons: No. 1-December 1995 and February 1996 samples, as well as 2 samples (day 0 and day 22 from the in vivo sample of parasites obtained from the blood collected in February 1996; No. 2-December 1995 and November 1996 samples; No. 3-May 1996 sample; No. 4-August 1996 sample; No. 5November 1996 sample collected from a person residing in Charco, the neighbouring village. A relatively conserved region of $m s p 1$ (block 17) was similarly analysed for all samples, in order to provide an internal control. Sequence analysis confirmed that for each marker, the fragments analysed were of the same size ( $151 \mathrm{bp}$ and $313 \mathrm{bp}$ for $m s p 1$ block 2 and block 17 respectively, and $428 \mathrm{bp}$ for $m s p 2$ block 3). The allelic family and the number of arrangements of the repeat units of the $m s p 1$ and $m s p 2$ regions sequenced were practically the same for all samples (Fig. 3). Therefore the results strongly suggest that the $P$. falciparum parasites circulating in Achada Leite from November 1995 to November 1996 are genetically homogeneous.

A few point mutations were noted between the different bacterial clones (Fig. 3): a single synonymous point mutation in the block 2 of $m s p 1 ; 6$ point mutations ( 5 of which were non-synonymous) in the block 17 of $m s p 1$; 4 point mutations ( 2 nonsynonymous) in the block 3 region of $m s p 2$. Since some of these point mutations were observed in different bacterial clones obtained from the same 
PCR reaction of a given sample, they were thought to result from amplification artefacts. This is consistent with the low fidelity of the Taq polymerase used, and the fact that the products cloned were obtained following a total of 55 amplification cycles.

\section{DISCUSSION}

We present in this article the first parasitological, molecular and longitudinal analysis of an isolated malaria outbreak. Three notable facts characterize this outbreak. The population affected was nonimmune, a single parasite line was responsible for all the infections observed, and parasites could still be detected in the inhabitants 1 year after the start of the outbreak.

Santiago Island can be considered as being in the consolidation phase of malaria eradication. No cases of malaria infections had been reported in the village of Achada Leite since 1990. The lack of previous exposure to malaria in the villagers is further supported by the number of persons infected (at least $41 \%$ ), and the fact that all age groups were infected. Although most infected persons developed clinical symptoms, the morbidity associated with the outbreak was low presumably due to the speedy deployment of active case detection and the distribution of anti-malarial drugs. It is unlikely that any significant transmission took place in the months following the start of the outbreak in October 1995 since very few new clinical cases were recorded after December 1995, and anti-larval measures were immediately instigated. Detection of ELISApositive (against CSP) inhabitants in May and June 1996, is not inconsistent with the above conclusion since it is known that antibodies against the CSP can persist long after exposure to the bite of infected mosquitoes (Druilhe et al. 1986; Wijesundera et al. 1990).

The most remarkable feature of the outbreak is that only 1 line of $P$. falciparum parasites could be detected in the inhabitants over the following year. The extent of diversity of the $m s p 1, m s p 2$ and glurp genes of $P$. falciparum is such that in endemic areas it is rare to find 2 persons with the same parasite populations (Mercereau-Puijalon et al. 1991; Babiker et al. 1994, 1995; Viriyakosol et al. 1994; Contamin et al. 1995; Färnert et al. 1997). The same allelic variants were, however, observed for all the samples analysed from Achada Leite. Sequencing of DNA amplified from a subset of samples obtained from the same or different persons during the study, confirmed that the same sequence is present in the repetitive polymorphic regions of the $m s p 1$ and $m s p 2$ genes of the $P$. falciparum parasites. It is therefore highly likely that the parasites circulating in Achada Leite represent a clonal population. To our knowledge, a similar situation has not been previously recorded. P. falciparum populations exhibiting very low diversity have been observed in malaria endemic areas which are usually characterized by low transmission levels or irregular resurgence of the infection. This type of situation was observed in an epidemic among a community of Yanomani amerinds in the Venezuelan Amazonian region (Laserson et al. unpublished observations, Tami et al. personal communication) or in Honduras (Haddad et al. 1999). Nonetheless, in these and other observations in endemic areas, some heterogeneity in the diversity of the $P$. falciparum parasites is invariably detected.

According to personnel from the PNLP, the outbreak followed an exceptionally wet season. This may have caused an increase of mosquito densities and longevity, and consequently a substantial increase in vectorial capacity (Ribeiro et al. 1980; Molineaux, 1988). In order for transmission to occur persons with circulating infectious gametocytes must be also present. It is unlikely that many such carriers were present on the island, since Achada Leite was the only village where malaria cases have been recorded during this period. As all the infections in this village were probably due to a clonal parasite population, it can be concluded with confidence that the outbreak originated from a single asymptomatic gametocyte-carrier (index case). The vectorial capacity in Achada Leite must have been exceptionally high in October 1995, since a large number of villagers became infected during this short period. The villagers were not aware of any recent immigrants or visitors to the village. However, the index case might have acquired a malaria infection a considerable time before the outbreak, and a gametocytaemia long after the initial infection would then be responsible for the outbreak. This possibility is supported by the observation in November 1996 of gametocytes in some of the villagers of Achada Leite.

The persistence of the infection in the community ( $44 \%$ of the population surveyed in February 1996) might have resulted from poor compliance to chloroquine treatment (4 doses). Despite switching to Fansidar treatment (single dose) in February 1996, villages with circulating parasites could still be detected in later surveys albeit in decreasing proportions. A more likely explanation is the resistance to chloroquine demonstrated using in vitro-cultured parasites. Resistance to chloroquine and Fansidar is common in parasites circulating in West Africa, where the index case most probably acquired the infection.

Knowledge of the average duration of $P$. falciparum infections in nature is of some importance to understanding the epidemiology of this parasite. There are serious obstacles to deriving such data from the study of malaria in endemic regions. The diversity of circulating parasites and frequent concurrent infections with multiple parasite lines, does not allow unequivocal identification and longitudinal 
follow-up of infections with a single parasite line. This is exacerbated by possible reinfections, which are difficult to distinguish from persistent parasitaemias. Data have been gathered from experimental $P$. falciparum infections in man, carried out for the treatment of neurosyphilis. In these infections, which were generally allowed to run their natural course with minimal subcurative treatment, clinical recurrences were most frequently observed in the first 6 months following the primary parasitaemia: with extended observation, parasites could sometimes be found up to 1 year following inoculation, and in exceptional cases for longer (Eyles \& Young, 1951; Garnham, 1966). These observations were nonetheless limited to adults, and the parasite lines used in malariatherapy were not necessarily genetically homogeneous. From the observations in Achada Leite, where reinfection beyond the period around October 1995 was unlikely, it is possible to conclude that $P$. falciparum infections can persist for up to 1 year in the natural host. The proportion of the population (around 10\%) with parasitaemia persisting beyond 6 months following the initial outbreak, is likely to be an underestimate. Indeed parasite levels often fall below the threshold of detection between recrudescences, which also tend to be of short duration (Kitchen, 1949). Thus, more frequent sampling from a large number of the inhabitants might have provided a higher number of villagers with persistent parasitaemia. Antigenic variation in malaria (Brown \& Brown, 1965) is thought to underlie the chronicity of the infection. The genome of $P$. falciparum is thought to contain up to 50 different var genes, which code for an antigenically variant surface protein (Baruch et al. 1995; Smith et al. 1995; Su et al. 1995), and a 2\% switch rate was obtained in vitro (Roberts et al. 1992). Duration of clonal infections for a year or more implies that the switch rate might be lower in vivo, immunity to variants might be short lived or that other proteins are involved in maintaining chronicity.

The potential of chronic malaria carriers to transmit malaria long after the initial infection is demonstrated by finding gametocytes in the blood of some of the villagers 1 year after the outbreak in October 1995. It is likely that the initial outbreak in Achada Leite resulted from an exceptional set of circumstances where the presence of infectious gametocytes in 1 person coincided with a short period when climatic conditions allowed the mosquito population to thrive. It is possible that a few chronic parasite carriers might be found in other areas of Santiago Island, where anopheline mosquitoes are widespread. The confinement of such an outbreak to only 1 village illustrates the importance of local factors in the epidemiology of malaria. It is reasonable to assume that a single person introduced falciparum malaria in Achada Leite, and that no further transmission took place after the initial outbreak. As at least 83 inhabitants of Achada Leite acquired the infection it would appear that the basic reproductive rate of the parasite was high $\left(R_{0}=\right.$ the average number of secondary infections derived from a single primary case in a susceptible population). The sudden declaration of the infection in a high proportion of the villagers would be consistent with a single round of transmission, although the data do not actually allow an unequivocal conclusion. Although high in the non-immune population of Achada Leite, $R_{0}$ might prove to be substantially lower if the parasites were to infect an immune population in a highly endemic area, as calculated in an elegant model of malaria populations, the Strain Theory, which has been recently elaborated (Gupta \& Day, 1994; Gupta et al. 1994). Clearly the value of $R_{0}$ will also vary according to local parameters such as the vectorial capacity and the susceptibility of the host population.

The outbreak we describe illustrates graphically the potential dangers associated with the reintroduction of malaria in areas where climatic and socioeconomic conditions allow for the presence of significant vector populations in close proximity of susceptible host populations. It will therefore be important that vigilance and the public health infrastructure associated with malaria control, are maintained for considerable periods in regions where the potential for the reintroduction of malaria is high.

In conclusion, observations of this outbreak due to a homogeneous $P$. falciparum population in an isolated malaria-free community have provided the opportunity to derive conclusions of parasitological significance. The duration of an infection due to a single line of $P$. falciparum in a non-immune host, can extend up to 1 year after the inoculation. Moreover, the observation of gametocytes at this stage of the infection implies that the parasite retains its potential for transmission despite a lengthy period of asexual multiplication in an immunocompetent host. These facts are pertinent to the elaboration and interpretation of epidemiological models of malaria. Furthermore, the observed lengthy chronicity of the infection is of some relevance to the nature of acquired immunity, in particular with respect to antigenic variation and its influence on clinical manifestations, and the maintenance of the parasitaemia. The rapid declaration of the outbreak and the extent of its spread in the community should be taken into account in the design and monitoring of long-term malaria control programmes.

We are indebted to the population of Achada Leite for their collaboration, to Teresa Casaca (IHMT, Portugal), Anabela Isidro, Luis Fonseca and Pedro Pechirra (CMDT, Portugal) for DNA extraction. This work was supported by PRAXIS/2/2.1/SAU/0.2/94 and PRAXIS/2/2.1/SAU/1415/95. 


\section{REFERENCES}

alves, J. (1994). Programme National de Lutte contre le paludisme. Plan d'Action 1994-1998. Ministère de la Santé, République du Cap-Vert.

BABIKER, H., RANFORD-CARTWRight, L., SUltan, A., SATTi, G. \& WALLIKER, D. (1994). Genetic evidence that RI chloroquine resistance of Plasmodium falciparum is caused by recrudescence of resistant parasites.

Transactions of the Royal Society of Tropical Medicine and Hygiene 88, 328-331.

BABIKER, H. A., CHARLWOOD, J. D., SMITH, T. \& WALLIKER, D. (1995). Gene flow and cross-mating in Plasmodium falciparum in households in a Tanzanian village.

Parasitology 111, 433-442.

BARUCh, D. I., PASlOSKE, B. L., SINGH, H. B., BI, X., MA, X. C., FELDMAN, M., TARASCHI, T. F. \& HOWARD, R. J. (1995). Cloning the $P$. falciparum gene encoding PfEMP1, a malaria variant antigen and adherence receptor on the surface of parasitized human erythrocytes. Cell 82, 77-87.

BAYOUMI, R. A. L., BABIKER, H. A. \& ARNOT, D. E. (1994). Uptake and efflux of chloroquine by chloroquine resistant Plasmodium falciparum clones recently isolated in Africa. Acta Tropica 54, 141-149.

Borre, M. B., DZIEgIEl, M., HøGH, B., PETERSEN, E., RIENECK, K., RILEY, E., MEIS, J. F., AIKAWA, M., NAKAMURA, K., HARADA, M., WIND, A., JAKOBSEN, P. H., COWLAND, J., JEPSEN, S., AXELSEN, N. H. \& VUUST, J. (1991). Primary structure and localization of a conserved immunogenic Plasmodium falciparum glutamate rich protein (GLURP) expressed in both the preerythrocytic and erythrocytic stages of the vertebrate life cycle. Molecular and Biochemical Parasitology 49, 119-131.

BROWN, K. N. \& BROWN, I. N. (1965). Immunity to malaria: Antigenic variation in chronic infections of Plasmodium knowlesi. Nature, London 208, 1286-1288.

cambournac, F. J. C., Petrarca, v. \& Coluzzi, M. (1982). Anopheles arabiensis in the Cape Verde archipelago. Parassitologia 24, 265-267.

Certa, U., Rotman, D., MATile, H. \& Reber-Liske, R. (1987). A naturally occuring gene encoding the major surface antigen precursor p190 of Plasmodium falciparum lacks tripeptide repeats. EMBO fournal 6, 4137-4142.

COLLINS, F. H., MEHAFFEY, P., RASMUSSEN, M., BRANDLINBENNET, A., ODERA, J. \& FINNERTY, v. (1988).

Comparison of DNA-probe and isoenzyme methods for differentiating Anopheles gambiae and Anopheles arabiensis (Diptera: Culicidae). Fournal of Medical Entomology 25, 116-120.

CONTAMIN, H., FANDEUR, T., BONNEFOY, S., SKOURI, F., NTOUMi, F. \& MERCEREAU-PUIJALON, O. (1995). PCR typing of field isolates of Plasmodium falciparum. Fournal of Clinical Microbiology 33, 944-951.

DRUilhe, P., PRAdier, o., MARC, J.-P., Miltgen, F., MAZIER, D. \& PARENT, G. (1986). Levels of antibodies to Plasmodium falciparum sporozoite surface antigens reflect malaria transmission rates and are persistent in the absence of reinfection. Infection and Immunity 53, 393-397.

EYLES, D. E. \& YOUNG, M. D. (1951). The duration of untreated or inadequately treated Plasmodium

falciparum infections in the human host. Fournal of the National Malaria Society 10, 327-336.

FÄRNERT, A., SNOUNOU, G., INGEGERD, R. \& BJÖRKMAN, A.

(1997). Daily dynamics of Plasmodium falciparum subpopulations in asymptomatic children in a holoendemic area. American Fournal of Tropical Medicine and Hygiene 56, 538-547.

GaRnhaM, P. C. C. (1966). Plasmodium falciparum and Plasmodium reichenowi. In Malaria Parasites And Other Haemosporidia, pp. 357-430. Blackwell Scientific Publications, Oxford.

GUPTA, S. \& DAY, K. P. (1994). A strain theory of malaria transmission. Parasitology Today 10, 476-481.

GUPTA, S., TRENHOLME, K., ANDERSON, R. M. \& DAY, K. P. (1994). Antigenic diversity and the transmission dynamics of Plasmodium falciparium. Science 263, 961-963.

HABluetzel, A., ESPosito, F. \& LOMBARdi, s. (1989). Immunotechniques for epidemiology of malaria: appropriate tools for integration of primary health cares with malaria research and control. Transactions of the Royal Society of Tropical Medicine and Hygiene 83, 15-19.

HADDAD, D., SNOUNOU, G., MATTEI, D., ENAMORADa, I. G., FIGUEROA, J., STÅHL, S. \& BERZINS, K. (1999). Limited genetic diversity of Plasmodium falciparum parasites in field isolates from Honduras. American Fournal of Tropical Medicine and Hygiene (in the Press.)

Kitchen, s. F. (1949). Falciparum malaria. In Malariology. A Comprehensive Survey of all Aspects of this Group of Diseases from a Global Standpoint, vol. II (ed, Boyd, M. F.), pp. 995-1016. W. B. Saunders Company, Philadelphia and London.

MERCEREAU-PUIJALON, O., FANDEUR, T., BONNEFOY, S., JACQUemot, C. \& SARThOu, J.-L. (1991). A study of the genomic diversity of Plasmodium falciparum in Senegal. 2. Typing by the use of the polymerase chain reaction. Acta Tropica 49, 293-304.

molineaux, L. (1988). The epidemiology of human malaria as an explanation of its distribution, including some implications for its control. In Malaria, Principles and Practice of Malariology, vol. 2 (ed, Wernsdorfer, W. H. \& McGregor, I.), pp. 913-998. Churchill Livingstone, Edinburgh.

PINTO, J., AREZ, A. P., FRANCO, S., ROSARIO, V. E. D., PALSSON, K., JAENSON, T. G. T. \& SNOUNOU, G. (1997). Simplified methodology for PCR investigation of midguts from mosquitoes of the Anopheles gambiae complex, in which the vector and Plasmodium species can both be identified. Annals of Tropical Medicine and Parasitology 91, 217-219.

Ribeiro, H., Ramos, H. C., CAPEla, R. A. \& PiRES, C. A. (1980). Os mosquitos de Cabo Verde (Diptera: Culicidae). Sistemática, distribuição, bioecologia e importância médica. Junta de Investigações do Ultramar, Lisbon.

Rieckman, K. H., CAMPBell, G. H., SAX, L. J. \& Mrema, J. E. (1978). Drug sensitivity of Plasmodium falciparum. An in-vitro microtechnique. Lancet i, 22-23.

Roberts, D. J., CRAig, A. G., BERENDT, A. R., PINChes, R., NASH, G., MARSH, K. \& NEWBOLD, C. I. (1992). Rapid switching to multiple antigenic and adhesive phenotypes in malaria. Nature, London 357, 689-692. 
SCOTT, J. A., BROGDON, W. G. \& COLlins, F. H. (1993). Identification of single specimens of the Anopheles gambiae complex by the polymerase chain reaction. American Fournal of Tropical Medicine and Hygiene 49, 520-529.

SMith, J. D., Chitnis, C. E., CRAig, A. G., ROBERT, D. J., HUdSON-TAYlor, D. E., PETERSON, D. S., PINChes, R., NEWBold, C. I. \& MILleR, L. H. (1995). Switches in expression of Plasmodium falciparum var genes correlate with changes in antigenic and cytoadherent phenotypes of infected erythrocytes. Cell 82, 101-110.

SMYthe, J. A., PETERSON, M. G., COPPEL, R. L., SAUl, A. J., KEMP, D. J. \& ANDERS, R. F. (1990). Structural diversity in the 45-kilodalton merozoite surface antigen of Plasmodium falciparum. Molecular and Biochemical Parasitology 39, 227-234.

SNOUNOU, G., VIRIYAKOSOL, S., ZHU, X. P., JARRA, W., PINHEIRO, L., ROSARIO, V. E. Do., THAITHONG, S. \& BROWN, K. N. (1993). High sensitivity of detection of human malaria parasites by the use of nested polymerase chain reaction. Molecular and Biochemical Parasitology 61, 315-320.

SU, X.-Z., HEATWOLE, V. M., WERTheimer, S. P., GUINET, F., HERRFELDT, J. A., PETERSON, D. S., RAVETCH, J. A. \& Wellems, T. E. (1995). The large diverse gene family var encodes proteins involved in cytoadherence and antigenic variation of Plasmodium falciparum-infected erythrocytes. Cell 82, 89-100.

TANABE, K., MaCKaY, M., GOMAN, M. \& SCAIFe, J. G. (1987). Allelic dimorphism in a surface antigen gene of the malaria parasite Plasmodium falciparum. Fournal of Molecular Biology 195, 273-287.

VIRIYAKOSOL, S., SIRIPOON, N., ZHU, X. P., JARRA, W., SEUGORN, A., BROWN, K. N. \& SNOUNOU, G. (1994). Plasmodium falciparum: Selective growth of subpopulations from field samples following in vitro culture, as detected by the polymerase chain reaction. Experimental Parasitology 79, 517-525.

VIRIYAKOSOL, S., SIRIPOON, N., PETCHARAPIRAT, C., PETCHARAPIRAT, P., JARRA, W., THAITHONG, S., BROWN, K. N. \& SNOUNOU, G. (1995). Genotyping of Plasmodium falciparum isolates by the polymerase chain reaction and potential uses in epidemiological studies. Bulletin of the World Health Organization 73, 85-95.

Wijesundera, M. D. S., PEIRIS, J. S. M., ARUiyaratne, y. G., VERDINI, A. S., PESSI, A. \& DEL GUIDICE, G. (1990). Antibodies to Plasmodium falciparum sporozoites following a malarial outbreak in a non-endemic area of Sri-Lanka. Transactions of the Royal Society of Tropical Medicine and Hygiene 84, 35-39. 